\title{
O DIREITO AO TRABALHO ACHADO NA RUA: O DESPERTAR DA SOCIEDADE E AS TRANSFORMAÇÕES SUBSTANTIVAS REQUERIDAS PELO MUNDO DO TRABALHO E PELO ESTADO DEMOCRÁTICO DE DIREITO
}

\author{
Cláudio Jannotti da Rocha ${ }^{1}$ \\ Lorena Vasconcelos Porto ${ }^{2}$ \\ Quenya Correa de Paula ${ }^{3}$
}

\section{Resumo}

O presente artigo tem como objetivo precípuo analisar o direito ao e do trabalho a partir do direito achado na rua, que é uma concepção inspirada no humanismo dialético do jurista Roberto Lyra Filho e que invoca o espaço comunitário para a conscientização de que há vida jurídica fora do universo oficial. Próxima do povo pobre e excluído, essa mirada interdisciplinar, em sua abordagem crítica, posiciona-se pela legitimidade dos movimentos sociais para combater a sociedade desigual em relação a qual o positivismo jurídico, assente no rigor cientificista, revela pouca sensibilidade por força do dogmatismo do sujeito absoluto idealizador. Sob essa égide, os autores preocupam-se em levantar a problemática de que para a máxima efetividade do Estado Democrático de Direito, deve-se tutelar o trabalho que é realizado nas ruas ou nas ações coletivas e não somente proteger as relações empregatícias, afinal, o direito ao trabalho é um direito fundamental, praticado pelo homem de maneira atemporal, onipresente e indeterminada, fruto dos movimentos sociais e onde se ressalta a existência da vida além das indústrias e fábricas, situação ora evidenciada pelos autores de direito ao trabalho achado na rua. A

\footnotetext{
${ }^{1}$ Professor Adjunto da Universidade Federal do Espírito Santo (UFES). Professor Titular do Centro Universitário do Distrito Federal (UDF), em Brasília-DF, e de seu Mestrado em Direito das Relações Sociais e Trabalhistas. Doutor em Direito pela PUCMG. Coordenador e Pesquisador do Grupo de Pesquisa: Processo, Trabalho e Previdência: diálogos e críticas, da UFES, com registro no Diretório dos Grupos de Pesquisa do CNPq. Pesquisador do Grupo de Pesquisa: Constitucionalismo, Direito do Trabalho e Processo, do UDF e do Grupo de Pesquisa: Trabalho, Constituição e Cidadania, da UnB - ambos com os respectivos registros no Diretório dos Grupos de Pesquisa do CNPq. E-mail: claudiojannotti@hotmail.com

2 Doutora em Autonomia Individual e Autonomia Coletiva pela Universidade de Roma II. Professora Titular do Centro Universitário UDF. Professora Convidada do Mestrado em Direito do Trabalho da Universidad Externado de Colombia, em Bogotá. Pesquisadora do Grupo de Pesquisa: Processo, Trabalho e Previdência: diálogos e críticas, da UFES, com registro no Diretório dos Grupos de Pesquisa do CNPq.E-mail: loreporto@yahoo.com.br

${ }^{3}$ Doutoranda em Direitos e Garantias Fundamentais pela Faculdade de Direito de Vitória (FDV). Pesquisadora do grupo de pesquisa “Direito, Sociedade e Cultura”. E-mail: quenyasc@hotmail.com
} 
metodologia utilizada neste artigo é a qualitativa, na modalidade descritiva, consubstanciada na pesquisa bibliográfica e documental à luz do ordenamento jurídico brasileiro e internacional.

Palavras-Chave: Direito achado na rua. Humanismo dialético. Movimentos sociais. Democracia. Direito ao trabalho

\section{INTRODUÇÃO}

Colocado entre as lentes alternativas no afầ de se voltar às emergências e necessidades sociais, o direito achado na rua, expressão cunhada por Roberto Lyra Filho, congloba as iniciativas de inspiração dialético-crítica em relação ao discurso jurídico oficial e dogmatizado, escudado no monismo e no paradigma da representação, funda o suporte do conhecimento na consciência e, assim, o elemento organizador se situa na reta razão relativamente ao pensar que despreza os conteúdos para deixar emergir a logicidade-formalista.

Ao se inspirar na práxis libertadora em relação ao determinismo burguês-capitalista, o rompimento com a colonialidade, que estigmatiza grupos e indivíduos, é previsto pela possibilidade concebida pela noção nova do fenômeno jurídico de guarida à representação semântica dos movimentos populares como possibilidade de escoadouro da pauta de carências da sociedade.

A presente reflexão se direciona à Nova Escola Jurídica Brasileira, particularmente o núcleo de pesquisa da UnB (com relevo, José Geraldo de Souza Júnior e Roberto A. R. de Aguiar), que enfatiza a sociologia comprometida no engajamento contra a espoliação e tendo o direito tomado do escopo progressista de promover a síntese superadora do naturalismo e do positivismo, a fim de empreender o ataque à alienação trazida pelo reducionismo da estatalidade, sob a égide do direito posto como única maneira de expressão da justiça.

Foi em torno do pluralismo e da decolonialidade do direito que os movimentos sociais, ao terem ignorado a sua presença como organizações atuantes, ao lado de operadores jurídicos, também incomodados com a expressão legislativa limitada, buscaram, no humanismo dialético de vezo social, a abertura para questionar a normatividade e a fetichização legalista, que tem como centro gravitacional a relação empregatícia. Afinal, as normas trabalhistas devem tutelar somente os empregados? Como ficam os trabalhadores que estão fora desta tipologia e que se encontram nas ruas, nos movimentos sociais e dentro da sociedade, os ditos invisíveis sociais? Como fica o direito ao trabalho achado na rua?

É da rua, como ponto de expressividade do povo pobre e coisificado (que fez surgir o Direito do 
Trabalho, vez que suas fontes materiais são greves e manifestações populares e sociais), que a palavra do sujeito coletivo descentralizado, a despeito da pressão exercida pelo habitus dogmaticus, que replica a formação bancária do ensino oficial, surge para influenciar as práticas renovadas visando fazer o direito se pronunciar a partir de sua essencialidade sociopolítica. É desse belvedere que se descortina a inclusão social para a garantia da efetividade dos princípios reitores do dirigismo constitucional, objetivando subvalorizar a subalternidade no sentido de encontrar atalhos contra-hegemônicos que permitam medidas não sintonizadas com o modelo eficientista da lógica de custos, que tem afastado do direito, mormente nas nações menos estruturadas economicamente, o compromisso com o teor substantivo das teses do poder constituinte, em especial as que têm em conta a concretização multidimensional dos direitos fundamentais.

Impende destacar que os autores deste artigo não possuem nenhum objetivo de trazer respostas exatas ou conceitos fantasiosos que resolvam o problema acima exposto, em um passe de mágica. Na verdade, eles estão preocupados em refletir, levantar questões, ampliar o debate acadêmico e, principalmente, contribuir para um aumento da efetividade do direito ao trabalho como um dos principais alicerces do Estado Democrático brasileiro, através do direito ao trabalho achado na rua.

\section{O DIREITO E OS ESPAÇOS PÚBLICOS}

O juspositivismo tem, na expressão normativista-kelseniana, índole descritiva vinculada a juízos de teor sancionatório e homogeneizados segundo o arquétipo antecedente/consequente, "[...] na forma de enunciados no sentido de que se tais e tais condições forem satisfeitas então deve-se proceder a tal e tal sanção" (KELSEN, 1992, p. 49). Destarte, a proposição jurídica se expressa como metalinguagem do direito positivo (o único objeto que respeita ao jurista psicologizado), utilizando-se do sintagma "dever-ser" para ligar as relações deduzidas dos fatos contidos nos enunciados normativos, ou seja, a manifestação concreta é dispensada, mantendo-se relevante, do ponto de vista científico, a objetividade do método, embora a aplicação do intérprete autêntico (juiz e/ou autoridade administrativa) termine por dar passagem à discricionariedade institucionalizada, como na livre apreciação da prova.

Para o estudioso vienense, ao fim, a leitura prescritiva, segundo a cisão sein/sollen, é influenciada por aspectos morais e políticos. Como quer que seja, na versão legalista-exegética (a compreensão como Auslegung) e em sua expressividade ligada às crenças da autoridade, o positivismo privilegia a validade em detrimento do conteúdo, vinculando a legalidade com a legitimidade.

O formalismo é, portanto, a pedra de toque da redução epistemológica positivista, na medida em que o chão da vida é estremado pelos limites do normativo estatal, marcando a desimportância da ambiência social. 
Logo, por força do logocentrismo, o agir dogmático sonega o que realmente se mostra, não permite que o ente se desvele verdadeiramente, joga a interpretação na zona do impessoal, desacopla a tradição e, ao privilegiar o assujeitamento das coisas à consciência em si do pensamento pensante, não se estabelece diálogo com o que é justo ou útil, porque a universalidade pretendida impõe a opção avalorativa e neutra, a fim de que o alinhamento com a matematização da natureza não sofra fissuras.

Do ponto de vista regido pela técnica e confinante do agir jurídico à dicotomia sujeito/objeto, flui o direito concebido como sistema normativo dotado de coatividade e imperatividade. Tal controle pelo Estado, visto no léxico marxiano em ligamento com a reprodução do capital, faz o alinhavo jurídico caminhar mediado pela restrição da capacidade do agir humano através da qual se desprezam as condicionantes históricas e sociais.

Para o direito achado na rua, o jus tem de ser pensado fundamentalmente como liberdade e emancipação, possuindo nas construções identitárias dos grupos e movimentos sociais a expressão legítima e o espaço de reconhecimento e o tempo de construção de experiências heterodoxas e não-conformistas. Para a gênese social do direito, a normatização pelo Estado é um incidente de percurso, porque, ao reduzir e condicionar, a ordem jurídica isola as outras formas de expressão em vigor dentro do espaço plural-coletivo, normatizando somente aquilo que ele entende como necessário ou produtivo, e por isso inclui o que quer e exclui aquilo que não quer ou que não lhe convém. Portanto, a depender do sujeito ou do objeto, a lei pode ser includente ou excludente.

O assenhorear do direito pela lógica do capital e dos segmentos opressores trava os manifestos em prol da autoconsciência de quão urgentes são as transformações substantivas requeridas pelo Estado Democrático de Direito associado à Teoria Material da Constituição, vilipendiando elementos nucleares como a dignidade da pessoa humana, a cidadania, a liberdade e a emancipação. Sendo assim, é nos espaços comuns, refletindo o cotidiano da sociedade e o percurso das lutas pelo reconhecimento e pelo pertencimento, que os sujeitos coletivos hão de se alertar ao esforço de reconceituação do direito apropriadamente à mudança do status vigente, na marcha da legítima organização em favor da liberdade no sentido substancial, refletindo a capacitação dos segmentos excluídos a produzir normatividade que reflita a participação política, não em função da renda, de ser branco ou amigo do rei, mas decorrente das carências dos relegados pelo patrimonialismo à condição de ferramenta e, principalmente pelo fato de todos serem iguais na condição humana, afinal o homem é a base, a razão e o epicentro de tudo, inclusive do Direito e da sociedade.

A desmistificação da unilateralidade oficial na produção jurídica visa a permitir ao trabalho comunitárioparticipativo irradiar centros de difusão crítica em relação ao tradicionalismo da política, que aponta, de forma insensível e comprometida por alianças espúrias com as oligarquias, à adesão ao credo elitista, a despeito da referência à solidariedade compor a cabeça da Lei Fundamental com a exigência de cooperação intersubjetiva 
para garantir o rol dos bens indispensáveis à vida boa ${ }^{4}$.

A rua, que fervilha de miseráveis e famintos, boias frias e desvalidos, catadores e desempregados, párias e mirrados, enfim, de gente ignorada e repelida, é o local das inter-relações se estabelecerem e encontrarem no humanismo dialético o fundamento para a síntese superadora, ou seja, através da negação da negação, a proposta lyriana de combater o jusnaturalismo e o materialismo positivista empenha-se na salvação coletiva por meio do exercício comunitário ensejador das manifestações jurídicas compatíveis ao surgimento das expressões genuinamente populares. É na rua, portanto, “[...] onde se dá a formação de sociabilidades reinventadas que permitem abrir a consciência de novos sujeitos para uma cultura de cidadania e participação democrática" (SOUSA JUNIOR, 2018, p. 277).

Neste sentido, ao contrário do que ocorre através da presente sistematização normativa brasileira, que deixa de reconhecer e de destinar direitos trabalhistas aos trabalhadores que se encontram nas ruas e nos movimentos sociais, simplesmente pelo fato delas não interessarem ao capital, bem como as grandes e oligárquicas empresas, criando assim uma série de trabalhadores excluídos da sociedade, podendo ser intitulados de invisíveis sociais. Justamente neste sentido, existem três importantes obras que demonstram e analisam esta situação, sendo elas: Introdução crítica ao Direito do Trabalho (SOUSA JÚNIOR; AGUIAR, 1993), Direito do Trabalho \& Trabalhos Sem Direitos (VIANA; TERRA; JUNIOR, 2000) e Trabalho Marginais (MAIOR; GNATA, 2013). O que se depreende atualmente do cenário jurídico brasileiro é uma gama significativa de trabalhadores considerados como invisíveis sociais por trabalharem nas ruas e nos movimentos sociais, que assim constituem um verdadeiro exército de trabalhadores que vivem à margem da sociedade, simplesmente por não estarem enquadrados dentro da tipologia normativa que a norma considera ideal para o sistema. Importante destacar, que esta conjuntura excludente do direito ao trabalho achado na rua, além de prejudicar estes trabalhadores, também viola em igual monta o Estado (que deixa de arrecadar os respectivos tributos), a sociedade (já que quantos menos contribuintes, maiores são os impostos), e até mesmo os sistema econômico (pois quanto menor o poder aquisitivo da pessoas, menores serão as vendas dos empresários e a circulação de renda e de produtos).

Esta exclusão normativa significa na verdade um verdadeiro afronto à ordem democrática, institucionalizada pela Constituição da República de 1988, vez que muito embora a democracia decorra da soberania popular, fazendo prevalecer a vontade de maioria, deve ao mesmo tempo respeitar os direitos das minorias, reconhecendo-as como sujeitas de direito, assim como a maioria é. A democracia advém, precisa e se efetiva no dissenso e não no consenso, aglutinando e harmonizando posicionamentos e pensamentos majoritários

\footnotetext{
${ }^{4}$ Art. $3^{3}$. Constituem objetivos fundamentais da República Federativa do Brasil: I - construir uma sociedade livre, justa e solidária;
} 
e contramajoritários, almejando e alcançando o equilíbrio, a segurança jurídica e a paz social. Neste caminhar, torna-se necessário que sejam criadas políticas públicas na perspectiva econômica, social, previdenciária, assistencial e jurídica para inserir as minorias na sociedade (dentre elas o direito achado nas ruas), lhes ofertando uma efetiva emancipação, liberdade e cidadania.

O que deve ser observado é que por de trás de todo e qualquer trabalhador, seja qual for a sua atividade, existe um ser humano, dotado de valores, sonhos, vontades e necessidades. Diferenciar as pessoas pelo trabalho que elas realizam é o maior equívoco que uma nação pode fazer ao conduzir a vida dos seus jurisdicionados, pois, assim, estratifica-se a sociedade por castas, sobreleva-se alguns e rebaixa-se outros, legitimando a manutenção de todo um sistema consumerista que acompanha o ser humano desde o seu nascimento, como o local que estudou e as oportunidades que teve ao longo de sua trajetória. Ora, ninguém escolhe uma família para nascer, tal fato decorre naturalmente e, o trabalho, deve corresponder a um instrumento capaz de ofertar a todos uma inclusão social, melhoria da condição socioeconômica, reconhecimento da sua dignidade e ainda, atingir o devido galardão e pertencimento a partir do labor que realiza.

Fato é que o ser humano é fruto ao mesmo tempo de sua genealogia, bem como do ambiente em que convive, e, por isso, a educação e o trabalho são elementos formadores e componentes da sua identidade, sendo as principais fontes de sua emancipação, libertação e cidadania, razão pela qual devem ser tutelados pelo Estado, mas, a partir das necessidades reais, estabelecidas e encontradas nas ruas e nos movimentos sociais e não de suposições ou achismos, frutos de um processo legislativo que não representa os anseios e as necessidades daqueles que estão à margem da sociedade e que fazem parte de uma gama muito significativa desta.

O trabalho, metaforicamente, deve corresponder a uma mola que deve propulsionar todo e qualquer ser humano em sua vida adulta, ofertando-lhe uma efetiva melhoria econômica e social, até porque sendo o Brasil um país poiético, nos termos ensinados por Joaquim Carlos Salgado (SALGADO, 1998, p. 15), o trabalho acaba sendo ao mesmo tempo uma atividade instrumental para os objetivos acima elencados, bem como também um meio para o acesso a outros direitos socais (estabelecidos no art. $7^{\circ} \mathrm{da} C R / 88$ ) que deveriam e não são fomentados pelo Estado como a saúde, educação, transporte, o lazer e a proteção a maternidade e à infância. Portanto, o trabalho diante deste cenário, torna-se o núcleo duro dos demais direitos sociais.

Diversos do homem ideal burguês, herdado da perspectiva liberal e tomado de modo abstrato, os sujeitos coletivos de direito, como o movimento negro, dos trabalhadores informais, das minorais, dos movimentos sociais e as comunidades eclesiais de base, ao ver da juridicidade pluralista alternativa, dotam-se de capacidade e legitimidade para lutar por interesses que lhes têm sido sonegados por um modelo de consequências funestas em termos de efetivação dos direitos fundamentais. 


\section{O DIREITO ACHADO NA RUA COMO PÁXIS LIBERTADORA}

Desde a Constituição da Mandioca, ${ }^{5}$ em que o voto censitário sublinhava a importância da pessoa pelo quantitativo de terras possuídas, a variável patrimonial perfaz o homem e estabelece a gradação de sua importância. A condição política, em termos de participação, ainda é determinada pela renda, pela procedência familiar, pela cor da pele e outros elementos de exclusão. Decerto, tanto a questão racismo como o sexismo são dados estruturais da cultura de superioridade do patriarcado e compõem a herança que tem como referência o proprietário como senhor da situação.

O direito, talhado ao modo da concepção privatista da felicidade e do individualismo da Ilustração, surge, no período moderno, como manifestação da classe que se levantava contra o absolutismo e o poder monárquico divinizado, servindo de instrumento para a garantia da circulação mercantil e, desse modo, a visão burguesa do justo deixava de fora o proletariado, submetido a excruciantes jornadas de trabalho, no período da revolução industrial, sem o mínimo indispensável à subsistência. A irresignação das massas, movidas pela pregação marxista contra a mais-valia apropriada para aumentar o capital e impor ao operário o sobretrabalho não remunerado, determinou a ascendência do Estado Social, sob o marco da revolução mexicana de 1917.

Conquanto a Carta de 1934 tenha captado a influência transformativa social em prol da quebra do substrato liberal até então adotado pelo constitucionalismo, o reconhecimento da condição do homem além do sentido apequenado pelo mercado e as construções elaboradas em torno dos direitos prestacionais não bastaram para atender, de fato, as necessidades vitais tidas como dever do Estado na atenção do bem comum. E não é preciso esforço para identificar o défice de realização constitucional, inclusive na Carta Magna de 1988, nos conduzindo para o "constitucionalismo simbólico" (NEVES, 2007, p. 44), porque a marca do país é um dos piores índices de distribuição de renda, sendo mostra disso o regime de exceção em que vivem comunidades inteiras cercadas pela insegurança e o medo na convivência com a criminalidade decorrente da crise de segurança.

Na verdade, o que se depara é que mesmo em pleno século XXI, o Brasil ainda tem um modelo de representatividade estabelecido e constituído na Revolução burguesa, final do século XVIII, fazendo e elaborando leis que são destinadas somente àqueles de participam diretamente do processo legislativo, para de alguma forma usufruírem delas, ainda que indiretamente. E através desta sistemática, o poderio econômico acaba fazendo que seus interesses particulares dominem o processo político e os ambientes do exercício do poder, dentre eles o

\footnotetext{
${ }^{5} \mathrm{O}$ projeto constituinte do Brasil independente, redigido pela assembleia de 1823, assumiu caráter machista e reverencial ao proprietário de terras, sendo o nome Constituição da Mandioca devido ao voto indireto em que os eleitores das paróquias (primeiro grau) deveriam provar uma renda mínima de 150 alqueires de farinha de mandioca. Os eleitores de segundo grau, por sua vez, precisavam de renda de 250 alqueires e, ao fim, a eleição de deputados e senadores demandava renda de 500 e 1.000 alqueires respectivamente para se candidatarem.
} 
Poder Judiciário que vinculado à normatização imposta pelo Poder Legislativo, acaba ofertando uma atividade jurisdicional no mínimo legitimadora dos interesses desta classe dominante, nos exatos termos lecionados Michel Foucault (FOUCAULT, 2002, p. 15).

Inegável que a vigente Constituição (um marco democrático no Brasil, que nos ofertou um significativo avanço normativo), institucionalmente, fornece espaço aos grupos minoritários demandarem as teses que lhe são caras, à conta da abrangência de assuntos que nela estão inseridos e do modelo misto de controle de constitucionalidade, mas o desarranjo intrassistêmico, a partir do imaginário metafísico-objetificante alinhado ao direito como autarquia, situa o conhecimento em alguma instância superior e exterior ao intérprete, seguindo a teoria da representação. Esse modo adstrito à filosofia da consciência ignora o plano fático e faz da fixidez à explicação causal (raciocínio silogístico) a chave para desvendar o sentido do texto e dele extrair respostas definitivas enraizadas em esquemas universais e acessíveis a todos, [...] com o que a autonomia do direito passa a depender da irredutibilidade de seu objeto aos fatos sociais que disciplina (MADALENA, 2016, p. 63).

Essa ignorância aos reclamos por uma resposta convincente em termos de sinceridade constitucional, além de ser antidemocrática, por valer-se de decisionismos na distribuição da justiça (o solus ipse do intérprete kelseniano), adia a real concretização do elo entre a política e o direito, previsto nas Constituições dirigentes do pós-segunda guerra, engendradas como verdadeiros planos globais para o futuro. A cooriginariedade entre direito e moral, conforme a gênese dos textos compromissórios, inviabiliza a convivência dos positivismos (o plural é devido) com a agenda transformadora do constitucionalismo comunitário, consoante a orientação axiológica do poder constituinte e que a cidadania espera ser respeitada independente das conviçcões partidárias de momento, ou seja, o vezo contramajoritário da vontade geral explicitada no instante de formação da ordem jurídica "[...] coloca, pois, em xeque o princípio da maioria, em favor da maioria fundante e constituinte da comunidade política (STRECK, 2013, p. 164).

Ocorre que, mesmo com a jurisdição constitucional atuante no sentido de solucionar os conflitos emergentes das demandas apresentadas, ao ponto de desatender a autocontenção e partir rumo a posturas ativistas, fato é que a microjustiça, como acontece nas causas envolvendo remédios e tratamentos de saúde, destinação de direitos trabalhistas somente aos empregados, uma educação precária e falha, além de afetar o orçamento e a receita estatal, compromete a generalidade e a igualdade das políticas públicas. Mas o protagonismo do judiciário para implementar os direitos de segunda dimensão, à míngua da representação popular, mais sintonizada com a agenda de setores com poder de lobby, é justificado quando se diz que tanto a teoria constitucional como o contexto sociopolítico brasileiro " [...] justificam não só a existência da jurisdição constitucional no País, como também o seu exercício proativo e independente em diversas áreas" (SOUZA NETO; SARMENTO, 2015, p. 85). 
Todavia a expansividade da atuação dos juízes, fundada no reconhecimento ampliado de direitos pelos cidadãos, incluindo os metaindividuais, vistos sob a perspectivação coletiva, remete ao rigor tecnicista e avalorativo, presente desde a formação universitária, para decidirem, à moda de uma mônada psíquica e segundo esquemas do cogito, como se não tivesse havido a revolução copernicana do direito público no sentido da aplicação direta dos princípios e regras constitucionais às relações privadas.

Além da desídia na busca pelo bem-estar, motivada pela ignorância da facticidade e da inserção da moral no direito, dada a sobrevivência do intérprete alheio à realidade do ser e, portanto, achegado à ontologia da coisa, os marginalizados também defrontam com a dificuldade de acionar o judiciário, pelo pouco aparelhamento das defensorias públicas, sujeitando-se à leniência das instituições em ofertar os bens que respeitam às normasprograma da Constituição, comprometendo as necessidades básicas como saúde e educação. No ponto em que a desigualdade impingida de cima abaixo pelos que manobram o poder de regulação decompõe o ambiente de convivência a altos níveis de toxidade, onde a ganância corruptiva e a má governabilidade sepultam as pretensões de vida decente aos desfavorecidos, à jurisdição, ainda que aproximada do conhecimento intelectual em deficiência da temporalidade e da finitude, cabe as respostas sonegadas pelos demais poderes, em especial as relativas aos débitos para os que têm pouca acessibilidade à formulação das políticas públicas.

O operador que envereda pela atitude solipsista (Selbstsüchtiger), aprisionando a verdade à linguagem codificada, menospreza a urgência de readequar sociologicamente o fenômeno jurídico ao processo históricosocial e, assim, assumir a atitude nova e pareada ao pluralismo, ao compartir com a escola crítica frankfurtiana "[... a conscientização e a emancipação dos sujeitos históricos na sua condição de dominados e excluídos" (WOLKMER, 2008, p. 88).

A multiplicidade, que admite a existência do direito fora do Estado, abre a válvula ao reconhecimento do combate em favor das reivindicações populares no sentido de afirmar direitos e trazê-los à liça independente das instâncias clássicas, que reproduzem as práticas patriarcais com fulcro na hegemonia etnocêntrica a inferiorizar os invisíveis, o negro, a mulher e demais sistemas de vida próximos da inferiorização.

A falta de sensibilidade ao que verdadeiramente se desvela, como é deduzido da visão silogística afeita ao esgotamento de sentido nas regras jurídicas, desconhece e ignora a rua, onde os despossuídos clamam pelos frutos que lhes são negados, onde a multidão se transforma em povo, onde a militância faz explodir a dor e o seu grito de alerta, onde a verdade desnuda prevalece, porque a rua é o lugar do protagonismo, " $[\ldots]$ do acontecimento, do protesto, da formação de novas sociabilidades e do estabelecimento de reconhecimentos recíprocos na ação autônoma da cidadania: autônomos: que se dão a si mesmos o direito (COSTA; SOUSA JUNIOR, 2009, p. 18).

É da participação popular ligada à priorização da juridicidade, definida segundo a expressão das mazelas existenciais do homem enquanto partícipe e produto do entendimento socialmente construído, que se costuram 
novas categorias jurídicas tendentes a acolher o pensamento não-conformista, cujo eixo de irradiação é o pluralismo participativo visando à criação de direitos empenhados na ética da vida feliz, ante os impasses da razão ocidental, que camufla a realidade para aceder ao saber meramente teorético. Isso significa colocar o direito na luta social constante, incorporada à dialética, de modo que não fique limitado a refletir a superestrutura normativa da produção estatal e, dessa maneira, "[...] o direito, em resumo, se apresenta como a positivação da liberdade conscientizada e conquistada nas lutas sociais e formula os princípios supremos da Justiça Social que nelas se desvenda" (LYRA FILHO, 1999, p. 88)."

A participação popular no intuito de escrever a história e nela inserir ganhos convincentes em termos do objetivo fundante de construir uma sociedade solidária e fraternal é o motor ainda não devidamente posto em movimento, por ausência de conscientização em torno da auto-organização política como força libertadora para a formar uma sociedade democrática e igualitária. Há de se considerar nesse raciocínio, como algo a ser enfrentado nesse processo de maioridade, o legado cultural de passividade política que marca a sociedade civil e o caráter inativo diante da centralidade do Estado, de modo que "[... prevalece em nossa nação a 'estadania, visto a ausência de uma cultura cívica, cabendo aos atores não estatais um papel de coadjuvantes nesse processo" (ANDRADE; CASTRO; PEREIRA, 2012, p. 188).

É contra a estatismo que a cidadania ativa deve incorporar formas plurais de manifestação acerca da produção jurídica local-comunitária, caracterizadas pela existência dos sujeitos em função dos movimentos de feição contestadora, solidarística e propositiva do projeto de mudança em prol das minorias e da soltura das amarras do tecnologismo, que jogou o direito nas formas idealizadas da conformidade do pensamento consigo próprio e, seguidamente, refutar a contradição dialética em prol da identidade entre o ser e o pensar.

\section{O DIREITO AO TRABALHO ACHADO NA RUA}

É incontroverso e pacífico o entendimento que de que todas as pessoas trabalham, via de regra, quando iniciada à vida adulta, sendo alguns antes e outros depois, para que assim possam alcançar o seu sustento, melhoria da condição socioeconômica, inclusão social e até mesmo para realizar seus sonhos.

Partindo da premissa de que o trabalho é a transformação da natureza de forma voluntária e consciente, almejando o homem atingir um determinado fim, tem-se que o trabalho acompanha o ser humano desde o seu próprio surgimento, porquanto no comunismo primitivo trabalhava para manter-se vivo, protegendo-se do frio, da fome e dos grandes animais, daí porque no comunismo primitivo os homens eram nômades, residiam em cavernas e alimentam-se da caça e da pesca (tendo inclusive criado utensílios para exercer estas atividades); posteriormente, durante a escravidão, a grande parte era considerada como objeto, pertencente ao senhor e era 
privado da sua liberdade, devendo trabalhar em troca de moradia e alimentação, independentemente do seu labor, sendo que os frutos deste ficavam para aqueles e não para ele, podendo eles mesmo serem vendidos ou trocados a sua própria revelia. Já no feudalismo poucas diferenças podem ser vislumbradas, mas pequenos avanços ocorreram, dentre eles o fato de que os servos ficavam vinculados à terra em que estavam estabelecidos, mas, sua liberdade ainda era vilipendiada, devendo permanecer, desde o seu nascimento, ao feudo que seus familiares se encontravam e ali trabalhavam. Os frutos do trabalho por eles realizados pertenciam ao senhor feudal.

Alcançado e institucionalizado o sistema capitalista, até porque a teoria da acumulação esteve presente na vida do homem ao longo de sua história, mesmo anteriormente ao Estado de Direito, onde, na perspectiva do constitucionalismo social do Século XX surge o Direito do Trabalho, um ramo autônomo e específico, dotado de regras, princípios e institutos próprios, que representa um dos principais vértices do Estado Democrático brasileiro, ofertando paz e segurança jurídica ao povo brasileiro. Na vigente normatização trabalhista tem-se que a modalidade de trabalho valorizada e regulamentada é a relação empregatícia onde um trabalhador preenche os cinco elementos fáticos jurídicos legalmente previstos: pessoalidade, trabalho prestado por pessoa física, onerosidade, habitualidade e subordinação. Portanto, somente os empregados possuem os direitos estabelecidos em lei, sendo que os demais trabalhadores não fazem jus aos direitos trabalhistas. Ou seja, aqueles que preenchem o estereótipo que a lei considera como bom e necessário para o sistema, têm os direitos regularizados, enquanto que aqueles trabalhadores que exercem uma atividade que a lei não considera como essencial para o sistema, não têm acesso aos direitos estabelecidos no ordenamento jurídico brasileiro, sendo que os menos favorecidos economicamente e que exercem atividades vulneráveis nas ruas e nos movimentos sociais - o direito ao trabalho achado na rua - acabam vivendo à margem da sociedade, inclusive na perspectiva previdenciária e até mesmo assistencial.

Portanto, a mesma lei ora inclui e ora exclui, tendo como critério determinante a modalidade de trabalho realizado pelo homem, conveniente ou não ao sistema ou aqueles que fazem as leis. Com isso desvaloriza-se o homem, para valorizar-se o que ele produz, a sua atividade e não a sua natureza humana, em que todos são iguais e por isso possuem as mesmas necessidades vitais para sobreviver. Será que de fato uma sociedade consegue alcançar uma prosperidade econômica, social e jurídica diferenciando as pessoas pelo trabalho que ela realiza? É justo exigir de uma pessoa que não teve acesso à educação de qualidade que ela exerça um trabalho intelectual ou manual que exija trabalho técnico ou científico qualificado - como é o caso do Brasil? Será que a lógica produtiva empresarial consegue subsistir sem que seja beneficiada pelo trabalho realizado pelos trabalhadores invisíveis socialmente? Pode-se pensar que existe qualquer ser humano ou empresa completamente independente ao ponto de não precisar de nenhum trabalho prestado por outra pessoa? Deve-se entender por sociedade cada um por si, vivendo isolado ou estratificado? 
É provável que todas respostas às indagações acima são negativas, vez que diferenciar as pessoas pelo trabalho que elas realizam significa dizer que algumas são melhores que as outras devido à atividade; todos nós somos iguais fisicamente e por isso nossos corpos precisam das mesmas necessidades para manter-nos vivos; não se pode exigir de alguém aquilo que a ela não foi ofertado ou ensinado; é impossível qualquer atividade empresarial (setor terciário) ou produtiva (secundário) conseguir ser realizada sem que faça uso do trabalho achado na rua (primário), geralmente exercido pelo excluídos sociais; nenhum ser humano consegue sobreviver ilhado ou isolado, afinal ele não nasceu para isso (é um ser-com) e, por sociedade, entende-se que os indivíduos devam estar de mãos dadas, ajudando uns aos outros numa relação de interdependência, pois, o que você não domina ou não sabe fazer, o próximo sabe e domina e dele você se beneficia e vice-versa.

É preciso aumentar o espectro tangencial das normas trabalhistas para que consequentemente ocorra um aumento no campo de atuação do Direito, na promoção da democracia (inclusão social) e do Direito do Trabalho, alcançando maior número de trabalhadores possíveis, inclusive os invisíveis que trabalham nas ruas e nos movimentos sociais e que, atualmente, encontram-se na situação de excluídos sociais. É a partir deste aumento tangencial normativo que a esfera jurídica-trabalhista estará acompanhando as mudanças do mundo do trabalho e até mesmo da sociedade. Em síntese: o direito ao e do trabalho devem abranger também o trabalho achado na rua.

Diante de todo o explanado o trabalho acompanha e faz parte da vida do homem, e a partir dele o ser humano se organiza, constitui sua residência e pauta sua rotina diária, seja ele realizado em qualquer modalidade. Este contexto ocorre desde o linear da humanidade e por isso, tem-se que o trabalho ao mesmo tempo que é inerente e necessário ao ser humano, também influencia na organização da sociedade. O trabalho "se faz presente em todos os lugares em que o homem ocupa espaço, como nas ruas, nas fábricas, nas esquinas, no sertão, nas indústrias, nas usinas, nas praias, nos restaurantes, nas residências, nas universidades, nas obras, nos supermercados, nas lanchonetes, nas carvoarias, no mato, nas florestas, nos lixões, na televisão e até mesmo em alto-mar e no ar" (ROCHA; PORTO, 2018), operando-se aí o direito ao trabalho, que deve consubstanciar o Direito do Trabalho.

Sendo assim, para que se tenha um Direito do Trabalho ainda mais democrático e efetivo formal e materialmente é necessário que suas normas sejam destinadas não somente aos empregados, mas também aqueles que se encontram presentes nas ruas, nos movimentos sociais e à margem da sociedade, afinal, do direito ao trabalho é um direito constitucional estabelecido no art. 6º da Constituição da República de 1988. Este amplo espectro normativo trabalhista dar-se-á pelo fato do trabalho ser atemporal, onipresente e impessoal, estando em todos os lugares, sendo praticado por todos e qualquer momento da história.

Fato é que na atual conjuntura as normas trabalhistas não conseguem alcançar um considerável contingente de trabalhadores que exercem atividades primárias e miseráveis, desvalorizada pelo capital, já que 
encontram-se fora da tipologia legal e com isso perde o Direito do Trabalho em sua abrangência, o Estado em sua arrecadação tributária e o trabalhador que fica relegado, ensejando assim um verdadeiro universo paralelo econômico, jurídico e social, formado por excluídos sociais.

Conforme dados recentes do IBGE, o número de pessoas em situação miserável no Brasil em 2016, era de 13,34 milhões, e aumentou para 14,82 milhões em 2017. Portanto, o que se vê é um aumento de 11\%, com 1,5 milhão de pessoas entrando na situação de extrema pobreza, sendo que uma das causas é justamente o desemprego e o ingresso destas pessoas no trabalho informal realizado nas ruas e nos movimentos sociais. Portanto, atualmente existem quase 15 milhões de trabalhadores brasileiros que não conseguem obter inclusão social, melhoria socioeconômica, o reconhecimento da dignidade e a efetivação da cidadania através do trabalho que realiza, pelo fato de na rua ou nos movimentos sociais o realizarem, e por isso não receberem nenhum resguardo normativo trabalhista. Caso este universo de invisíveis sociais fosse incluído na formalidade brasileira, certamente que o ganho seria substancial para todos, incluindo o Estado brasileiro na arrecadação tributária.

Metaforicamente, podemos imaginar que o Direito do Trabalho é uma rede de pesca onde o Estado é o pescador. Caso ela tenha espaçamentos grandes entre as linhas, pegará somente peixes grandes e, provavelmente, em pequena quantidade já que os pequenos passam pelos espaços. Agora, se o Estado trocar de rede, e nesta outra os espaçamentos forem menores, inquestionavelmente, esta nova rede será mais eficiente, ofertando ao pescador pegar mais peixes, melhorando assim a sua pescaria. O mesmo raciocínio aplica-se ao Direito do Trabalho já que quanto mais as suas normas forem condizentes com o trabalho realizado nas ruas e nos movimentos sociais, ou seja, além das fábricas e das industrias, inquestionavelmente, ele se tornará mais efetivo, tutelando um maior número de trabalhadores, que, até a presente data são considerados como invisíveis sociais. Assim, ganha o Estado na arrecadação tributária e receita e ganha o trabalhador com sua inclusão social e normativa.

Por isso, o Direito do Trabalho deve estar antenado e acompanhar os anseios das ruas, dos movimentos sociais, das colônias de pescadores, das associações, dos sindicatos e das comunidades para que cada vez mais, menos pessoas sejam excluídas a partir de norma que é constituída pelo processo legislativo, sob pena de ruptura da ordem democrática, que muito embora deva ser direcionada pela vontade da maioria, não pode olvidar os anseios e as vontades da minoria.

Se o trabalho é inerente ao homem, e se dele ele vive e se realiza, inclusive alcançando sua subsistência, emancipação, reconhecimento e pertencimento, o direito ao trabalho também deve ser inerente ao homem, seja qual for a atividade realizada. Aliás, estando o trabalho inserido na sociedade, o próprio direito ao trabalho, inclusive o achado na rua, deve partir e estar dentro dela.

Diante da importância do trabalho na sociedade e na vida do ser humano, a vigente Constituição da República brasileira o estabelece como um dos fundamentos da República Federativa do Brasil (art. 1, IV), bem 
como um dos alicerces da ordem econômica (art. 170) e da ordem social (art. 193), e por isso os direitos trabalhistas estabelecidos constitucionalmente alcançam o status de direitos fundamentais (SARLET, 2015, p. 77), devidamente estabelecidos e elencados no art. 7o, e destinados a todos os trabalhadores brasileiros, conforme previsão legal do caput, fomentando assim aos trabalhadores o direito fundamental ao trabalho digno (DELGADO, 2017, p. 209). Portanto, na democracia institucionalizada no Brasil, o direito fundamental ao trabalho é condição de exigibilidade (WANDELLI, 2012).

E, por isso, torna-se necessário que o movimento expansionista do direito ao trabalho seja devidamente efetivado e que estas normas constitucionais trabalhistas sejam também destinadas a todos os trabalhadores brasileiros e não somente aos empregados, já que nos exatos termos lecionados por Jorge Americano, a interpretação restritiva só pode ocorrer por previsão legal e não pelo intérprete. Sendo assim, não tendo a lei feito qualquer restrição no art. $7^{\circ}$ da Constituição, é vedado ao interprete assim fazer (AMERICANO, 1932, p. 234).

Reconhecer a importância do trabalho na sociedade significa democratizar as relações intersubjetivas, bem como abrir as portas para a inclusão social de grande parte da população: classe trabalhadora. Afinal, se o trabalho permite o ser humano alcançar uma melhoria de vida, da sua condição socioeconômica e até mesmo o reconhecimento e o pertencimento a um determinado segmento de classe, corolário lógico que deve ser devidamente normatizado para que assim alcance o consectário e necessário patamar legal e tão logo fomente à sociedade a necessária segurança jurídica, típica do Estado de Direito, principalmente o Democrático que exige uma plena simbiose entre os anseios populares e sociais com a normatização que lhe é destinada. Portanto: se o direito ao trabalho é achado na rua e dela emerge as respectivas necessidades, o Direito Constitucional e o do Trabalho devem absover estes clamores e de alguma maneira fomentar a inclusão social dos trabalhadores, sob pena de nos depararmos com o Estado Poiético, nos exatos termos lecionados por Joaquim Carlos Salgado (SALGADO, 1998, p. 34).

\section{CONCLUSÃO}

O direito achado na rua foi concebido para despertar nas classes populares a necessidade de incentivar a participação coletiva ciente da urgência de reduzir as desigualdades e realizar o bem-estar social, que, apesar de colocado na essência do Estado intervencionista prestigiado pelo poder constituinte, fica a dever a sua implantação em face do receituário da economia neoclássica, como núcleo teórico do neoliberalismo, de que a melhor política pública é não ter política alguma, com larga passagem ao rentismo financeiro e aos mercados desregulamentados como mecanismo de regulação social.

A própria vigente Constituição foi afetada, em sua configuração originária, pelas emendas que, em algum 
modo, a descaracterizaram para acolher as determinações do capitalismo planetário, não mais contido pelas fronteiras nacionais, dados os organismos e foros informais que ordenam a economia-mundo, consoante instâncias difusas de poder cujas interconexões se fazem tracionadas pela financeirização. A articulação que se sustenta no eixo de interesses hegemonistas das grandes corporações empresariais permite apenas os direitos possíveis de compatibilização com o arco de interesses particulares, embora o constitucionalismo social ainda reserve espaço para a invasão, nas manifestações concretas do direito, da axiologia que lineia a Lei Fundamental no seu estofo dirigista, sendo que a abertura hermenêutica passa longe do equívoco da metafísica sediado na objetificação. Desse jeito, cabe fazer o direito marchar obediente à percepção social da dignidade, originada nos espaços de comunicação social, isto é, metaforicamente falando, localiza-se na rua o centro de participação, o lugar de encontro e do pulsar da existência, o lugar do discurso das parcelas alijadas do debate, como ocorre, por exemplo, com as mulheres, que, tradicionalmente, têm de se inserir no mundo masculino para valerem suas plataformas e, em decorrência, se põem sob o enlace da inferiorização que caracteriza a colonialidade de gênero.

O humanismo trabalhado por esse direito vivo, advindo do chão da história contada pelos movimentos organizados em busca da justiça social, não vislumbra o indivíduo como ente absoluto mas elemento consagrador da politização objetivando a ênfase dos direitos humanos num patamar de maior reverência cotidiana. Nesse intuito, avulta a emergência pelo encontro das novas gerações com o ensino jurídico sob o horizonte interdisciplinar e de proximidade dos conflitos sociais, a fim de possibilitar que a juridicidade não se esgote no poder dominante do Estado, admitindo-se, sob a inspiração crítica, superar a autossuficiência juspositivista e, através do pluralismo das fontes, permitir que venha, na esteira da práxis concreta, o respeito à alteridade em nome do resgate dos grupos colonizados e marginalizados. É na rua que se realizará a resistência contra a impermeabilidade do sistema jurídico às concepções alternativas do direito. É lá, onde a vida civil ativa acorda para o empoderamento da participação popular para exigir direitos, ainda que contra legem, que se dará o despertar do papel coadjuvante a que a comunidade tem sido relegada pelo oficialismo.

E, no que tange ao direito do e ao trabalho, tem-se que para se tonar ainda mais efetivo deve ser capaz de tutelar e proteger o trabalho achado na rua, realizado por todos aqueles trabalhadores que laboram nas ruas e nos movimentos sociais, ditos invisíveis sociais e que na presente data são excluídos da sociedade. Fechar os olhos para o trabalho achado nas ruas, significa excluir da sociedade milhões de pessoas afastando-as do direito ao trabalho, e corolário lógico também do Direito do Constitucional e do Trabalho, fato que caminha em sentido contrário ao Estado Democrático de Direito, que não comporta a exclusão social, mas tão somente inclusão do ser humano, norma básica deste modelo organizacional e a razão de tudo. 


\title{
THE RIGHT TO WORK FOUND IN THE STREET: THE AWAKENING OF SOCIETY AND THE SUBSTANTIVE TRANSFORMATIONS REQUIRED BY THE WORLD OF WORK AND BY THE DEMOCRATIC STATE OF LAW
}

\begin{abstract}
The main objective of this article is to analyze the right to work based on the law found on the street, which is a conception inspired by the dialectic humanism of the jurist Roberto Lyra Filho and invokes the community space for the awareness that there is life outside the official universe. Next to the poor and excluded, this interdisciplinary approach, in its critical approach, is positioned by the legitimacy of social movements to combat unequal society in relation to which legal positivism, based on scientific rigor, reveals little sensitivity due to the dogmatism of the absolute, idealizing subject. Under this aegis, the authors are concerned to raise the problem that for the maximum effectiveness of the Democratic State of Right, it is necessary to protect the work that is carried out in the streets or collective actions and not only to protect the employment relations, the right to work is a fundamental right, practiced by man in a timeless, ubiquitous and indeterminate way, the fruit of social movements and where the existence of life beyond industries and factories is emphasized, as evidenced by by authors of right to work found on the street. The methodology used in this article is the qualitative one, in the descriptive modality, embodied in the bibliographical and documentary research in light of the Brazilian and international legal order.
\end{abstract}

Keywords: Right found on the street; Dialectical humanism; Social movements; Democracy; Right to Work.

\section{REFERENCIAS}

AMERICANO, Jorge. Do Abuso do Direito no Exercício da Demanda. 2a ed. São Paulo: Saraiva \& Comp Editores, 1932.

ANDRADE, Daniela Meirelles Andrade; CASTRO, Carolina Lescura de Carvalho; PEREIRA, José Roberto. Cidadania ou "estadania" na gestão pública brasileira? Revista de Administração Pública. Rio de Janeiro, v. 46, n. 1, 2012. Disponível em: <http://bibliotecadigital.fgv.br/ojs.index.php/rap/article/view/7081/5636>. Acesso em 10 fev. 2018 
COSTA, Alexandre Bernardino; SOUSA JUNIOR, José Geraldo. O direito achado na rua: Uma ideia em movimento. In: COSTA, Alexandre Bernardino et all. Introdução crítica ao direito à saúde. Brasília: CEAD/UnB, 2009.

DELGADO, Gabriela Neves. Direito Fundamental ao Trabalho Digno. 2a ed. São Paulo: LTr, 2017.

KELSEN, Hans. Teoria geral do direito e do estado. Tradução de Luís Carlos Borges. São Paulo, Martins Fontes, 1992.

LYRA FILHO, Roberto. O que é direito? São Paulo: Brasiliense, 1999.

MADALENA, Luis Henrique. Discricionariedade administrativa e hermenêutica. Salvador: Juspodium, 2016.

MAIOR, Jorge Luiz Souto; GNATA, Noa Piatã Bassfel. Trabalhos Marginais. São Paulo: LTr, 2013.

NEVES, Marcelo. A constitucionalização simbólica. 3a ed. São Paulo: Saraiva, 2014.

ROCHA, Cláudio Jannotti da; PORTO, Lorena Vasconcelos. O contrato de trabalho no Brasil: análises legais contemporâneas. Este artigo será publicado na Revista do Mestrado em Direito do Trabalho da Universidad Externado de Colombia, em Bogotá. Mimeografado.

SOUSA JUNIOR, José Geraldo. Direito como liberdade: O direito achado na rua: Experiências emancipatórias de criação do direito. Tese (Faculdade de Direito) - Universidade de Brasília, 2008. Disponível em: <http://www.repositorio.unb.br/bitstream/10482/1401/1/TESE_2008)JoseGeraldoSJunior.pdf>. Acesso em 05 fev. 2018.

SOUSA JUNIOR, José Geraldo de; AGUIAR, Roberto A. R de. Introdução Crítica ao Direito do Trabalho - série o Direito Achado na Rua - v. 2. Brasília: Universidade de Brasília, 1993.

SOUZA NETO, Cláudio Pereira de; SARMENTO, Daniel. Controle de constitucionalidade e democracia: Algumas teorias e parâmetros de ativismo. In: SARMENTO, Daniel (Coord.). Jurisdição constitucional e política. Rio de Janeiro: Forense, 2015. 
SALGADO, Joaquim Carlos. Estado ético e Estado Poiético. Revista do Tribunal de Contas do Estado de Minas Gerais, Belo Horizonte, v. 27, n. 2, p. 37-68, abr./jun, 1998.

SARLET, Ingo Wolfgang. A eficácia dos direitos fundamentais: uma teoria geral dos direitos fundamentais na perspectiva constitucional. 12. ed. Porto Alegre: Livraria do Advogado, 2015.

STRECK, Lenio Luiz.Jurisdição constitucional e decisão jurídica. 3. ed. São Paulo: Editora Revista dos Tribunais, 2013.

VIANA, Márcio Túlio; TERRA, Luciana Soares Vidal; JUNIOR, Décio de Abreu e Silva. Direito do Trabalho \& Trabalhos Sem Direitos. Belo Horizonte: Mandamentos, 2008.

WANDELLI, Leonardo Vieira. O Direito Humano e Fundamental ao Trabalho: fundamentalização e exigibilidade. São Paulo: LTr, 2012.

WOLKMER, Antonio Carlos. Introdução ao pensamento jurídico crítico. 6. ed. São Paulo: Saraiva, 2008.

Trabalho enviado em 16 de julho de 2018

Aceito em 19 de setembro de 2018 